\title{
ALEXANDRE EULALIO E O MODERNISMO
}

\author{
Silvia Quintanilha Macedo
}

s.quintanilha@ig.com.br

\begin{abstract}
O enriquecimento da crítica literária tem que se dar assim, em nosso meio, pela interpenetração não apenas com a Sociologia (...) mas principalmente com a História e a Antropologia, muito em especial com esta última, com a Psicanálise e com o urgente conhecimento da teoria e da prática das outras artes. Não se trata da proposição de um novo Ecletismo mas da instrumentalização de saberes complementadores que contribuem de modo decisivo para a operação hermenêutica (EULALIO, 1993, p. 15).
\end{abstract}

Iniciando muito jovem na imprensa, em 1952, Alexandre Eulalio (1932-1988) começa a publicar alguns artigos na universidade e também em jornais de grande circulação, entre os quais ganham destaque o Correio da Manhã e O Globo, segundo o levantamento proposto por Carlos Augusto Calil e Maria Eugenia Boaventura na revista Remate de Males (1993),em número especialmente dedicado ao estudioso diamantino.

Ele se projetaria de fato com o ingresso na Revista do Livro em 1956, fundada nesse mesmo ano, que também viu nascer os suplementos literários de O Estado de São Paulo e do Jornal do Brasil (MARTINS, 1977-1978, p. 365-366).

A crítica literária brasileira, "seguindo o ciclo do jornalismo, desde o século XIX, a caixa de ressonância da literatura do país" foi, segundo Benedito Nunes, "regularmente veiculada pelos jornais das duas 
metrópoles, Rio e São Paulo (Correio da Manhã, Diário de Notícias, A Manhã, O Estado de São Paulo, Jornal do Brasil) - antes que seus autores as enfeixassem em livros" (NUNES, 200o, p. 61).

Tema deste artigo, o livro A aventura brasileira de Blaise Cendrars, escrito em 1966, situa-se bem próximo das atividades de Alexandre no campo da pesquisa histórico-literária e como editor, experiências intelectuais cuja síntese é capaz de explicar a configuração da obra. O "caráter de colaboração coletiva", que lhe atribui o crítico, refere-se ao formato que ele dá à edição, organizada por meio de "reportagens, crônicas, ensaios, álbum, seleta, registro de gravações, livro de figuras, roteiro de filme, documentário" (EULALIO, 1978, p. 7).

Entre os temas já tratados anteriormente pelo autor, destaca-se o interesse pelo modernismo brasileiro, observado, sobretudo, através da ênfase na figura de Mário de Andrade. A pesquisa sobre as ligações entre Cendrars e o Brasil confirma, sem dúvida, a importância que o estudo do Modernismo exerceu no ideário eulaliano.

Adotar parâmetro teórico que ajuda a compreender e explicar a composição de livro tão significativo como A aventura brasileira de Blaise Cendrars levou-nos a selecionar três autores. Eles souberam identificar certos procedimentos a partir dos quais poderemos conduzir a leitura desta proposta admirável, original no universo da crítica literária brasileira.

Uma das melhores análises sobre o pensamento crítico de Alexandre Eulalio é de José Guilherme Merquior, chamada apropriadamente de "O demônio do perfeccionismo" (1993, p. 291-296). Merquior constata o avanço do formalismo na teoria literária durante o século XX e de sua hegemonia nos centros universitários. Disto resulta a formação de um paradigma de tipo interpretativo, que deixa de lado a dimensão explicativa da crítica, sua vertente contextualista.

Na sequência, ele considera a participação de Brito Broca e Augusto Meyer como os mentores de Eulalio, no plano nacional, de uma maneira crítica que adota explicação de ordem histórica e interpretação de caráter formal.

Augusto Meyer comparece relacionado ao aprendizado de sensibilidade da forma e da leitura imanente do texto, inspirada na estilística. A valorização pioneira da obra de Brito Broca ilustra o interesse de Alexandre Eulalio pelo enfoque na vida literária como meio de enriquecer a crítica interpretativa, voltada para os condicionamentos sociais. A ênfase no contexto, no entanto, supera, de acordo com Merquior, o modelo inspirado em Brito Broca, porque integra o senso da forma e a atenção mais apurada para o estético. 
Alexandre tratou de negar a legitimidade dessa separação entre forma e processo social, e o fez soberanamente. Essa foi uma de suas contribuições à crítica brasileira, talvez por mobilizar armas de erudição incomuns, com um conhecimento de literatura e época ímpar no contexto nacional (MERQUIOR, 1993, p.292).

Refletir sobre o método de leitura crítica de Alexandre Eulalio significa ainda apontar a opção por um sistema de notas cuja função é acolher os inúmeros detalhes, resultado de uma profunda preocupação do historiador "saturado de sapiência histórica" (MERQUIOR, 1993, p. 295).

A distinção feita em seguida entre os conceitos historista e historicista serve para definir que o primeiro, ao contrário do segundo, não revela "qualquer preocupação com o marco do processo histórico e com grandes etapas da evolução histórica”. Historista, Alexandre Eulalio demonstra uma disposição profunda para mergulhar num contexto específico, produzindo uma crítica eminentemente detalhista, que dispensa uma tese central e incorpora uma massa de conhecimentos históricos extremamente específicos. Disto resulta a importância das notas, como meio de conduzir um emaranhado de vias interpretativas e hipóteses explicativas (MERQUIOR, 1993, p. 294-295).

Outra referência que identifica orientação teórica semelhante é o registro de João Luiz Lafetá, debatedor na apresentação realizada por Alexandre de "A Literatura em Minas Gerais no século XIX", no III Seminário sobre a cultura mineira - século XIX, em Belo Horizonte, e publicado dois anos mais tarde, em 1982. Lafetá louva a capacidade que o autor tem de acumular dados histórico-culturais com um espírito de abrangência e minúcia que o deixou "assustado e um pouco soterrado. Erudição espantosa, de datas, fatos, obras e autores” (LAFETÁ, 1992, p. 127).

A intervenção salienta, no estudo de Alexandre Eulalio, o traçado que prioriza as grandes dimensões, sem perder de vista o pormenor. A leitura considera o ensaio como se tratasse de uma pintura: "painel de amplas proporções - um pouco ao gosto de certa pintura heróica do século XIX que nos atrai pela majestade da cena apresentada, mas também nos prende pelos detalhes trabalhados e minuciosos de uma ou outra passagem" (LAFETÁ, 1992, p. 126) .

A tensão observada entre painel e detalhe, estratégica para a compreensão do pensamento crítico de Alexandre Eulalio, é particularmente esclarecedora conforme a conclusão seguinte: "Se há a linha horizontal que persegue cem anos de história literária, há também algumas linhas verticais, cortes em profundidade, que pescam e exibem 
com mais profundidade algum personagem do painel" (LAFETÁ, 1992, p. 126).

Ao segundo momento, o mergulho vertical, o analista denomina "síntese fulgurante", capaz de trazer à tona uma ideia ou personagem apreendidos "com traço fino, sempre penetrante", o que permite destaque "da massa mais ou menos indistinta da composição global" (LAFETÁ, 1992, p. 126).

O vasto repertório, que garante a Alexandre Eulalio uma maneira particular de conduzir a reflexão crítica, não prioriza uma visão da obra reduzida a documento da realidade social ou enfocada apenas em seus elementos de fatura. Como bem observou Vinícius Dantas,

\footnotetext{
Na mania detalhista do perito, havia uma porção de devaneio e, principalmente, paixão pela matéria tal como ela é produzida e plasmada pela imaginação de um fazer técnico. Havia igualmente o desejo de encontrar algo concreto que justificasse a realidade menos palpável, mas realidade ao quadrado, da criação literária. Alexandre queria assim ensinar a ler a tessitura dessas relações múltiplas e históricas com lupa e paciência (DANTAS, 1993, p. 333).
}

De acordo com Carlos Augusto Calil, Alexandre Eulalio gostaria de publicar seu ensaio sobre Blaise Cendrars, mas não pensava em revista, preferindo o livro. A ideia de juntar o texto com o roteiro do filme rodado por Calil foi o início de A aventura brasileira de Blaise Cendrars.

Acompanham o ensaio central muitas notas, mencionadas no sumário, referido como "Tela Panorâmica": "Notas à Aventura". O segundo ensaio é "Nota (sem música) do Milhaud brasileiro", também seguido de "Notas à nota (sem música)", "aquele desenho que vem na capa do Le formose" e suas "Notas a ..aquele desenho".

No próximo item da "Tela Panorâmica”, figura: "Tempo brasileiro: esboço da cronologia de Cendrars com a gente", composto com Carlos Augusto Calil, assim como "Álbum de fotografias ruins". "Xerox (documentários)" reúne artigos de escritores brasileiros sobre Cendrars. Em "Filme com imagens", Alexandre apresenta o filme de Calil, que assina também a introdução "Cendrars: fita e realidade" sobre a história das filmagens de "Acaba de chegar ao Brasil o bello poeta francez Blaise Cendrars".

O último item da "Tela Panorâmica", "Elogio do homem fulminado" resume as considerações finais de Alexandre Eulalio sobre o texto final de Cendrars, escrito pouco antes de morrer. O crítico decifra no manuscrito referências ao Brasil, começando pelo ensaio principal, cuja consideração inicial indica que a ligação de Cendrars com o Brasil constitui um tema importante entre os contemporâneos brasileiros do 
poeta, que conviveram com ele na década de 1920, conforme afirma o crítico em "Xerox (documentários)", explicando o significado dessa seção. Entretanto, em relação a Alexandre Eulalio, o amadurecimento desse episódio na biografia literária de Cendrars parece ocorrer com a sugestão de Brito Broca, que, já em 1952, escreve "Blaise Cendrars no Brasil, em 1924":

\footnotetext{
"Xerox (documentários)" reúne - literalmente, como não podia deixar de ser - um leque de manifestações brasileiras sobre Cendrars, aberto, aqui, desde os primeiros constactos dos "novos" Anos 20 com a obra e a figura humana do grande poeta (EULALIO, 1978, p. 139).
}

Segue um breve comentário de cada um dos autores selecionados nesse primeiro momento. Merece destaque a atitude de Mário de Andrade:

Amo sobretudo, da poesia viva de França, Blaise Cendrars, porque o mais rico em benefício para mim. Ele me libertou da incompreensão do passado, pelo qual eu não vivia na terra do meu país e do meu tempo. Livrou-me do ritmo impessoal, dando-me não o seu, mas o meu ritmo; tão diferentes estes! (EULALIO, 1978, p. 142)

O reconhecimento de Blaise Cendrars como uma figura já integrada no passado começa a surgir, de acordo com Alexandre, a partir de um artigo de Tarsila, de 1938. A celebração histórica do poeta ocorre no Brasil, prossegue o crítico, em 1952, com Brito Broca, que: "com documentação ainda insuficiente, procura estabelecer as coordenadas dos contatos de Blaise, em 1924, com os amigos modernistas". Compensando os dados escassos, Alexandre destaca a

finura das observações interpretativas. É bem o caso daquela que ilustra o sentido da excursão "modernista” a Minas Gerais (aqui transcrita), abordagem pioneira no tempo pela visão clara, direta, do relacionamento intrínseco entre tradição e modernidade (EULALIO, 1978, p. 144-145).

O ensaio "A aventura brasileira de Blaise Cendrars" é composto de seis partes. A primeira delas recupera a imagem do menino Cendrars, leitor apaixonado de Júlio Verne, que legou ao futuro poeta a paixão pelas viagens. $\mathrm{O}$ destino de viajante traz a marca simbólica da estrela, segundo Alexandre Eulalio depreende de "O Eubagem (nos antípodas da unidade)”, uma das primeiras produções de Cendrars, que prenuncia sua trajetória poética. 
As narrativas de viagens, em verso ou em prosa, tornar-se-ão a maneira de organizar, como experiência vivida, na mais livre das associações, os elementos díspares encontrados pelos quatro cantos do mundo. Os contrários reunidos, os extremos que se tocam, magia e ciência, civilização e primitivismo, ordem e caos são enfim considerados como versões complementares e simultâneas de experiências humanas idênticas (EULALIO, 1978, p. 12).

Na complexa formação cultural de Cendrars, dentro da qual se destaca a vertiginosa modernidade da década de 20, integra-se a experiência brasileira: "Este espaço livre - espaço aberto dos descobrimentos e da aventura tradicional - torna-se para Cendrars, particularmente depois da sua descoberta do Brasil em 1924, o próprio símbolo da viagem que é encontro consigo mesmo" (EULALIO, 1978, p. 14).

A ligação vital estabelecida com a literatura é um critério muito forte, no momento de Alexandre eleger autores para os quais sempre retorna como influência, amizade, modelo de conduta: Joaquim Felício dos Santos, Mário de Andrade, Brito Broca, Blaise Cendrars. Além desse vínculo, a relação com a cultura brasileira funciona como outro critério que a figura de Cendrars só confirma.

De volta ao ensaio, a segunda parte justifica o interesse que o Brasil, "imenso laboratório de cultura", teria para esse viajante. Alexandre refaz aqui o percurso intelectual do poeta entre 1912 - já com o "seu prestígio literário consolidado" - e 1919, quando "a nomeada de Cendrars chega ao auge".

Nesse segmento, o ensaísta focaliza o encontro entre Cendrars e Darius Milhaud, que esteve no Brasil com Claudel, de 1917 a 1919, a serviço da diplomacia francesa. Depois de reconstituir rapidamente o episódio brasileiro dos dois franceses, o crítico explica a parceria Milhaud-Cendrars, que colabora na composição do ballet La création du monde, um trabalho de Milhaud:

Darius Milhaud foi sem dúvida o primeiro intelectual a despertar a curiosidade de Cendrars pelo Brasil. Conhecedor do singular temperamento do amigo novo, o compositor percebeu sem dúvida o interesse que a experiência de um mundo inteiramente inédito - dessa paisagem deveras anônima, conforme Gobineau a classificara com hepático mau humor cinquenta anos antes - iria provocar no poeta do Panamá (EULALIO, 1978, p. 16).

A mesma orientação para a historiografia literária manifesta-se no terceiro trecho do ensaio. Dessa vez, Alexandre reconstrói a livraria Americana do antiquário Chadenat, onde ocorreu o encontro entre Cendrars e Paulo Prado. Trata-se do ilustre sobrinho de Eduardo Prado (um "bibliófilo" convicto), colecionador de livros raros sobre o Brasil, 
discreto mecenas do modernismo, "intelectual disponível mas dotado de vigoroso senso prático".

Demora-se no retrato de Paulo Prado, já adiantando a amizade duradoura que este manterá com Cendrars. O crítico aproveita para detalhar o ambiente intelectual parisiense, onde se encontrava grande parte dos jovens modernistas brasileiros, bem como nomes importantes da vanguarda europeia. Mas apenas Cendrars se transformará em grande amigo.

No entanto, é Paulo Prado que obtém a atenção do crítico:

O vivo interesse de Paulo Prado pelo passado nacional, e que há de despertar a curiosidade de amigos mais jovens por este tipo de estudos, fora condicionado pela impressão esmagadora que lhe haviam causado os ensaios de interpretação empreendidos por João Capistrano de Abreu (EULALIO, 1978, p. 20-21).

De acordo com Alexandre, o interesse de Paulo Prado pela história, principalmente o período colonial, influencia toda uma geração de intelectuais: Caio Prado Júnior, o pintor Yan, Sérgio Buarque de Hollanda, Sérgio Milliet, Rubens Borba de Morais.

Ainda nessa parte três, o crítico indaga: "até que ponto Cendrars sopraria sugestões a esses jovens reunidos em Paris?" (EULALIO, 1978, p. 22). Sem dúvida, o papel exercido pelo autor de Retrato do Brasil surge com especial destaque:

Era Paulo Prado quem velava sobre a História, quem fazia ler aos amigos moços as crônicas e os documentos coloniais, muitas vezes comparáveis pelo mordente da escrita a algumas das melhores sínteses e elipses dos poetas de vanguarda (EULALIO, 1978, p. 22-23).

A quarta parte trata das viagens de Cendrars, quantas foram, e a poesia que produz no período. O texto crítico acompanha mais de perto a composição dos livros, a linguagem que o poeta adota, as diferenças entre os textos que ele publica ao longo do tempo. As "fotografias verbais" de Le formose, o despojamento formal de Feuilles de Route, "a prosa candente" de L'Or, o texto sincopado de Moragine, "cujo equilíbrio se reparte entre lirismo e paródia". Outros livros são citados como integrantes de uma segunda fase da poética cendrarsiana: "quase nenhuma das obras de Cendrars, neste segundo período, negligenciará o Brasil” (EULALIO, 1978, p. 28).

O próximo segmento retoma a abordagem histórica, recuperando os fatos que cercaram a chegada do poeta ao Brasil, como o episódio de humor negro encenado por Mário de Andrade, a viagem a Minas, as visitas que faz às fazendas de café de Paulo Prado. 
Alexandre ainda demora-se na pesquisa das reações negativas que a presença do poeta despertou. Mas não deixa de destacar o depoimento de Sérgio Milliet, que sublinha a força da poesia cendrarsiana sobre a sensibilidade dos modernistas brasileiros.

O sexto aspecto apontado diz respeito à grande expectativa de Cendrars quanto à possibilidade de fazer fortuna no Brasil. A convivência com Paulo Prado desperta certas ambições no espírito do poeta, justifica Alexandre, que ainda se detém no rompimento entre Cendrars e Oswald de Andrade.

O final do texto comenta alguns projetos anunciados de Cendrars que não se realizaram como Aleijadinho ou Histoire d'un sanctuaire brésilien: "O título faz pensar num ensaio consagrado ao grande arquiteto, decorador e escultor do Rococó mineiro, mas o projeto é curiosamente indicado como romance" (EULALIO, 1978, p. 41).

Considera ainda o contato profundo com o Brasil, e a literatura como experiência de vida. Quanto ao primeiro tópico temos: "Aprendiz de uma realidade onde sabia também estar contido, Cendrars tentou chegar além das aparências e alcançar a raiz amarga do Brasil“ (EULALIO, 1978, p. 43).

E quanto ao segundo: "Tudo isso é literatura, mas literatura vivida por um grande poeta. Um poeta que procurou tomar o pulso do mundo e consegue surpreender-lhe o ritmo na sua obra generosa" (EULALIO, 1978, p. 43).

A composição mais geral de A aventura brasileira de Blaise Cendrars adota uma perspectiva ampla, através da qual se examina o impacto do país na obra e personalidade de Cendrars. Em sentido inverso, explicitase a maneira como a influência do poeta franco-suíço vai deixando suas marcas entre os produtores da cultura modernista brasileira.

\footnotetext{
Depois das primeiras experiências, Cendrars passa a aceitar a realidade brasileira como uma iniciação, quase como uma iniciação anti-intelectual. (...) A sua solução consistirá na aceitação crítica de um real que nos aparece como contraditório e mesmo caótico. Desse ponto de vista a aventura brasileira de Blaise Cendrars foi ao mesmo tempo em que um esforço de aceitação do outro, uma jornada a mais para o conhecimento de si mesmo, das suas possibilidades de homem - um pretexto no sentido gideano (EULALIO, 1978, p. 41).
}

Embora o poeta suíço seja o centro do projeto, colado à sua figura, sobressai um conjunto expressivo de nomes ligados às artes e ao pensamento brasileiros. Isto se dá sobretudo no terreno das ideias críticas, representadas por Sérgio Milliet, Gilberto Freyre, Wilson Martins, Brito Broca, Sérgio Buarque de Hollanda, Mário de Andrade, Oswald de 
Andrade, Prudente de Moraes Neto, Manuel Bandeira. Todos no papel de cronistas, críticos, comentadores. Por meio dessas manifestações desenvolve-se a história moderno-modernista, encenada através dos vários registros colhidos, que contribuem tal como uma antologia para a composição do livro.

A seleção mostra não só os desdobramentos do Modernismo ao longo do tempo, como também a variação dos pontos de vista referentes aos seus diversos representantes.

É o caso, por exemplo, de Sérgio Milliet, cuja trajetória intelectual pode ser percebida na escolha de seus textos presentes no livro. Os depoimentos, notas e críticas de Milliet ajudam a compor o seu próprio retrato intelectual, paralelo ao de Cendrars.

Nesse sentido, encontramos Milliet envolvido com a vibração do primeiro momento modernista; segue um posicionamento de maturidade da crítica millietiana na década de 40. O texto de 1966 é marcadamente memorialista, o último escrito por Milliet, pouco antes de morrer.

Dentro do conjunto mais amplo do livro, a presença de Sérgio Milliet se integra e dialoga com as outras participações. O perfil de Cendrars vai sendo montado por esse jogo superposto de visões diferenciadas. Reforça o procedimento a seção "Retrato falado: 3x4", constituída por depoimentos de Sérgio Buarque de Hollanda e Prudente de Moraes Neto, de Tarsila do Amaral e de Marie Lebrun da Silva, viúva de Paulo Prado.

A pesquisa de natureza histórica está em toda parte: nos comentários às fontes que remetem aos textos selecionados e, principalmente, na cronologia que Alexandre faz juntamente com Carlos Augusto Calil, sobre as relações entre o poeta e o Brasil:

\footnotetext{
[...] ela [a cronologia] procurou basear-se em elementos palpáveis recolhidos por outros e por nós mesmos, em arquivos contemporâneos: cartas, fotos, postais, notas em revistas, apontamentos avulsos, retalhos de jornais velhos. A eles acrescentamos o trilho escorregadio das indagações espalhadas pelo próprio Cendrars nos livros por ele datados do Brasil, conseguindo desse modo uma proposta aproximativa em que realidade e ficção iluminam-se respectivamente (EULALIO, 1978, p. 94).
}

Ainda a propósito desse ensaio, vale observar que, embora não muito extenso, conta com um número bastante expressivo de notas, conforme reconhece o próprio autor: "um artigo sobrecarregado de notas como o nosso". Essa vocação para notas amplia-se no livro, sob a forma de artigos independentes, como acontece com "Nota (sem música) sobre o Milhaud brasileiro", ao qual se acrescem as "Notas à nota sem música". 
Mesmo no ensaio "Aquele desenho que vem à capa do 'Le Formose”, aparece acrescido: "Notas àquele desenho". Tanto esse trabalho associado à pintura de Tarsila quanto aquele referente à música de Milhaud e ao filme de Carlos Augusto Calil remetem à obra de Blaise Cendrars.

"Nota (sem música) sobre o Milhaud Brasileiro" mostra como o músico francês deixou-se envolver pela música brasileira, "aquela que se executava nos bares, nos jardins públicos, nas salas de espera dos cinemas, feiras, bailes populares, associações carnavalescas" (EULALIO, 1978, p. 78).

A viagem ao Brasil dá a Milhaud matéria para recriar a nova atmosfera que reencontra na Paris dos anos 20. Alexandre identifica nas peças para piano de Milhaud esse traço próprio da cultura musical carioca, que ainda guardava resquício do Rio imperial.

$\mathrm{O}$ ensaio dedicado a Tarsila do Amaral é bem diferente, pois o crítico faz uma minuciosa descrição de um quadro específico, A negra. Mesmo lembrando as influências dos mestres da pintora, escolhe uma abordagem que coloca em primeiro plano a obra e seus recursos de composição.

Fica, em relação ao conjunto do livro, um diálogo subterrâneo com o cubista Cendrars: fragmentação, colagens, simultaneidade, montagem e roteiro cinematográficos, sobreposição cubista, referência enfim ao vanguardismo do artista, que os desenhos, cartões, fotografias , pinturas, folhetos espalhados pelo livro reforçam .

Mais do que tal impressão, o resultado revela um estudioso à vontade nas diversas áreas em que já vinha circulando desde a década de 5o. Mostra ainda o perfeito domínio no manejo de uma quantidade infinita de informações, fontes diversas, pequenas histórias, leituras de toda ordem - o traço erudito enfim tão marcante desta personalidade intelectual. A vontade analítica demonstrada pelo ensaio alia-se à orientação mais geral dada à pesquisa, que se enriquece com o exercício ensaístico no terreno da literatura, das artes plásticas, da música e do cinema.

Essa multiplicidade disciplinar resulta em uma atitude crítica, já também cultivada por Eulalio em seus textos mais antigos: a visualidade nas descrições de cenas e personagens; a voz do narrador, minucioso na construção das paráfrases, o crítico literário à procura do mecanismo de construção do texto; o historiador da cultura que, por sua vez, narra igualmente os detalhes arrolados.

A aventura brasileira de Blaise Cendrars é ilustrativo de uma das principais características da poética crítica eulaliana, que traz a marca do editor da Revista do Livro, não exatamente em relação à abordagem 
filológica ou erudita, mas à possibilidade de lidar com áreas culturais diferentes, como a música, a literatura, o cinema, o teatro, as artes plásticas, a história da cultura. Alexandre juntou todas as áreas em um livro, que contou com a parceria cinematográfica de Carlos Augusto Calil.

Revendo somente o ensaio, podemos concluir que o autor diamantino também estabeleceu muitos nexos com sua experiência anterior, ao escolher para estudar Cendrars. O poeta suíço torna-se uma figura emblemática, porque consegue aglutinar muitas peças que formam o universo intelectual eulaliano.

No centro do círculo que envolve Cendrars está Paulo Prado, figura de forte representatividade nos estudos de Eulalio, trazendo o passado brasileiro do Conselheiro Antonio Prado, de Eduardo Prado, de Afonso Arinos, a maioria dos quais retratados pelo escritor diamantino. Eles representam uma determinada face do país: politica e economicamente poderosa e ilustrada, estudiosos da história brasileira, mecenas.

Cendrars é europeu, encarna o movimento artístico mais avançado da Europa; Alexandre mostra o impacto que a presença do suíço vanguardista causa nos moços modernistas.

A síntese Cendrars-Paulo Prado foi certamente perseguida, ao longo dos anos 50 e início dos 6o. Ela representa os dois pólos do imaginário de nosso autor. Desse encontro o modernismo ganha um lastro: a viagem a Minas, a Poesia Pau Brasil, a pintura de Tarsila, O retrato do Brasil.

A força do estudo que dá nome ao livro está, exatamente, na percepção dessas duas vertentes que se completam: nem o Brasil das grandes famílias, nem a Europa moderna, mas as duas coisas juntas e, portanto, transformadas. Existe algo mais estranho que a dedicatória que Cendrars faz ao Conselheiro Antonio Prado, na reportagem sobre Febrônio? Essa combinação agrada a Alexandre. O imaginário exacerbado, o dilaceramento da loucura, misturados à dramática situação brasileira ganham uma dimensão respeitosa. Na análise das "Aventuras de Cendrars”, verificamos a atração do crítico pela relação concreta, vivida, que o poeta mantinha com sua própria arte.

Refletindo sobre a técnida de composição do volume, já mencionamos a interferência da prática editorial de Alexandre. Entretanto é visível o movimento próprio do cinema, como elemento de construção.

Carlos Augusto Calil afirmou, em entrevista à autora, que teve decidida participação na organização da obra, recorrendo à técnica da montagem cinematográfica. Por isso, não foi difícil partir para a segunda edição da "Aventura": com o roteiro programado na edição anterior, a ampliação do material deveria obedecer ao mesmo modelo. 
De qualquer modo, o cubismo criou um estilo cinematográfico, pois o cinema é uma arte multidimensional como o cubismo. O diálogo entre o poeta cubista, o historiador do modernismo e o cineasta resulta na criação de um livro que, embora de natureza ensaística, tem um forte apelo imaginativo, de inspiração modernista.

De outro lado, fixemos a figura de Paulo Prado, que inspira em Alexandre o estudo da história do Brasil, o gosto de colecionar livros raros, a ligação com Capistrano de Abreu, a continuidade que dá à mesma paixão pela história cultivada pelo tio Eduardo Prado.

Em seu ensaio sobre Cendrars, o autor enumera vários escritores modernistas que descobrem a historiografia inspirados por Paulo Prado. Parece-nos que ocorre o mesmo com Alexandre, tantos anos depois, confirmando a profunda ligação que mantem com o modernismo.

A pesquisa que envolve a figura de Cendrars incorpora uma modalidade de conhecimento histórico marcado por escolhas de forte caráter pessoal. Carlos Augusto Calil declara que, se fosse obrigado a reduzir a "múltipla e surpreendente" personalidade do crítico a uma única característica reveladora, não hesitaria em apontar a obsessão pela "pesquisa da identidade pessoal e social" (CALIL, 1993, p. 383).

Nessa perspectiva, a produção intelectual de Alexandre Eulalio resulta "das suas fidelidades sentimentais à causa do Império, a Diamantina, ao mestre Brito Broca, ao Modernismo, ao encontro da contingência histórica ao campo estreito da realização individual" (CALIL, 1993, p.320). Na esfera da identidade cultural, é visível o empenho em demarcar os limites da memória, de salvar textos e biografias, principalmente de autores secundários, dos quais Alexandre Eulalio retira "insuspeitas relações com o inconsciente coletivo” (CALIL, 1993, p. 383).

Merquior atribui a essas escolhas do escritor diamantino um sentido de comprometimento com projetos estéticos vinculados à Modernidade, cujo ponto alto é a pesquisa em torno de Blaise Cendrars; o registro seguinte diz respeito à sensibilidade especial para o Decadentismo, que faz de nosso autor um intérprete agudo do gosto e do espírito decadentista. São influências que inspiram os estudos sobre Joaquim Felício dos Santos, a paixão por Diamantina e um inventário de temas que inclui a escolha de Esaú e Jacó entre os romances de Machado de Assis e a obra de Cornélio Pena (MERQUIOR, 1993, p. 295).

Sebastião Uchoa Leite estabelece uma relação semelhante quanto à duplicidade da posição de Alexandre Eulalio, "interessado no processo evolutivo da nossa cultura" e, ao mesmo tempo, um "cosmopolita de primeira hora” (LEITE, 1993, p. 324). Esta última constatação refere-se à descoberta apaixonada que o jovem redator da Revista do Livro faz, 
nos inícios da década de sessenta, de "um dos valores mais cosmopolitas do século XX“, Jorge Luis Borges, autor que Alexandre Eulalio também traduziu.

Mas a observação de Sebastião Uchoa Leite não apenas registra essa veia cosmopolita, considerando ainda o fascínio de nosso autor por dois temas borgeanos, que esclarecem pontos fundamentais do percurso trilhado pelo crítico. O primeiro deles diz respeito à questão do duplo, aspecto essencial da indagação sobre a identidade. $O$ segundo tema remete à interseção entre o real e o imaginário. "Alexandre certamente viveu essa equivalência, deixando-se fascinar pela ficção da arte e até, de certo modo, por uma ficção da história, de tal forma que isso terminou por invadir a sua vida" (LEITE, 1993, p. 324).

\section{REFERÊNCIAS BIBLIOGRÁFICAS}

CALIL, Carlos Augusto. Obra futura. Remate de Males. Alexandre Eulalio Diletante. Revista de Teoria Literária da Unicamp. Carlos Augusto Calil, Maria Eugenia Boaventura (Org). Campinas, 1993.

. Livro involuntário. Biografia discreta. In: Livro involuntário. Literatura, História, Matéria E Modernidade. Carlos Augusto Calil, Maria Eugenia Boaventura (Org). Rio de Janeiro: Editora UFRJ, 1993.

DANTAS, Vinicius. Retratinho de Alexandre. Remate de Males. Alexandre Eulalio Diletante. Revista do Departamento de Teoria Literária da Unicamp. Carlos Augusto Calil e Maria Eugenia Boaventura (Org). Campinas, 1993.

EULALIO, Alexandre. A aventura brasileira de Blaise Cendras. São Paulo: Quiron; Brasília: INL, 1970.

. A aventura brasileira de Blaise Cendrars. 2. ed. revista e ampliada por Carlos Augusto Calil. São Paulo: Editora da Universidade de São Paulo / Fapesp, 2001.

LAFETÁ, João Luiz. Debatedor da palestra: EULALIO, Alexandre. A literatura em Minas Gerais no século XIX. In: EULALIO, Alexandre. Escritos. Berta Waldman; Luiz Dantas (Org). Campinas: Editora da Unicamp; São Paulo: Editora da Unesp, 1992.

LEITE, Sebastião Uchoa. Alexandre, o memorioso. Remate de Males. Alexandre Eulalio Diletante. Revista do Departamento de Teoria Literária da Unicamp. Carlos Augusto Carlos Augusto Calil e Maria Eugenia Boaventura (Org). Campinas, 1993.

MACEDO, Sílvia Quintanilha. Alexandre Eulalio: retrato de um intelectual singular. Tese de Doutoramento. Faculdade de Filosofia, Letras e Ciências Humanas da USP, 2004.

MARTINS, WILSON. A crítica literária no Brasil. 2.ed. Rio de Janeiro: Francisco Alves, 1983. 
MERQUIOR, José Guilherme. O demônio do perfeccionismo. Remate de Males. Alexandre Eulalio Diletante. Revista do Departamento de Teoria Literária da Unicamp. Carlos Augusto Calil e Maria Eugenia Boaventura (Org.). Campinas, 1993.

NUNES, Benedito. Crítica literária no Brasil, ontem e hoje. In: MARTINS, Maria Helena (Org). Rumos da crítica. São Paulo: SENAC; São Paulo: Itaú Cultural, 2000.

Revista do Livro. Rio de Janeiro, Instituto Nacional do Livro. Ministério da Educação e Cultura, 1956-1970. 43 volumes. 
Resenhas 
